\title{
Is a follow up endoscopic retrograde cholangiography procedure necessary for removal of biliary stent?
}

\author{
Shashank Ponugoti
}

Follow this and additional works at: https://researchrepository.wvu.edu/etd

\section{Recommended Citation}

Ponugoti, Shashank, "Is a follow up endoscopic retrograde cholangiography procedure necessary for removal of biliary stent?" (2015). Graduate Theses, Dissertations, and Problem Reports. 6432.

https://researchrepository.wvu.edu/etd/6432

This Thesis is protected by copyright and/or related rights. It has been brought to you by the The Research Repository @ WVU with permission from the rights-holder(s). You are free to use this Thesis in any way that is permitted by the copyright and related rights legislation that applies to your use. For other uses you must obtain permission from the rights-holder(s) directly, unless additional rights are indicated by a Creative Commons license in the record and/ or on the work itself. This Thesis has been accepted for inclusion in WVU Graduate Theses, Dissertations, and Problem Reports collection by an authorized administrator of The Research Repository @ WVU. For more information, please contact researchrepository@mail.wvu.edu. 


\title{
IS A FOLLOW UP ENDOSCOPIC RETROGRADE CHOLANGIOGRAPHY PROCEDURE NECESSARY FOR REMOVAL OF BILIARY STENT?
}

\author{
SHASHANK PONUGOTI \\ Thesis dissertation submitted to the School of Medicine at \\ West Virginia University \\ in partial fulfillment of the requirements \\ for the degree of \\ Master of Science \\ in \\ CLINICAL AND TRANSLATIONAL SCIENCES
}

December 18, 2015

Kim E Innes, PhD, Chair

Sijin Wen, PhD

Fred Minnear, PhD

Department of Biomedical Sciences/Public Health

Morgantown, West Virginia

2015

Key Words: Bile leak, biliary stent, sphincterotomy, ERCP

Copyright @2015ShashankPonugoti 


\title{
ABSTRACT \\ Is a follow up endoscopic retrograde cholangiography \\ procedure necessary for removal of biliary stent?
}

\begin{abstract}
Shashank Ponugoti
Follow up endoscopic retrograde cholangiopancreatography (ERCP) procedure is routinely performed to remove biliary stents. Simply removing the stents is feasible with upper endoscopy (EGD), which costs less, is technically less challenging, is likely to be more comfortable for the patient, and is safer from a sedation perspective. But therapeutic interventions requiring ERCP may preclude this option. The aim of this study was to analyze the utility of follow up ERCP for biliary stent removal and to determine if follow up ERCP procedure is necessary in all patients. The study population comprised 284 adults who had undergone ERCP for stent placement and stent removal at the WVU Endoscopy Center between January 2005 and December 2011. Detailed information on each patient was obtained from medical records. Patients were categorized into five groups - those with bile leak alone $(\mathrm{N}=31)$, choledocholithiasis $(\mathrm{N}=127)$, benign stricture $(\mathrm{N}=77)$, malignant stricture $(\mathrm{N}=44)$ and bile leak with stone or stricture $(\mathrm{N}=5)$. On follow up ERCP, only $16 \%$ of patients in the bile leak group required therapy. In contrast, $90 \%$ of patients with choledocholithiasis, $82 \%$ of patients with benign stricture and $100 \%$ of patients in the remaining two groups required therapy that could only be accomplished with follow up ERCP. The two most common employed therapies in follow up ERCPs were stone or sludge removal $(57 \%)$ and stent replacement $(35 \%)$. Conclusions: In this retrospective study spanning 7 years, only $16 \%$ of patients with uncomplicated bile leak required a follow up ERCP for stent removal, whereas ERCP related interventions were needed at follow-up in $82-100 \%$ of patients with other conditions. Larger prospective studies are needed to confirm these findings and to determine if EGD might serve as a viable and cost effective alternative to ERCP in cases of uncomplicated bile leak.
\end{abstract}




\section{DEDICATION}

This work is dedicated to my parents, Laxminarasimha Rao, Vasumathi

Ponugoti. Thanks most of all for the endless encouragement, support, and sacrifice, which made this possible. 


\section{ACKNOWLEDGEMENTS}

First, I would like to thank my mentor Fred Minnear for his direction and guidance with my education and this thesis project. Most of all, I would like to thank him for the ability to direct and evaluate this thesis project and the science involved, while still encouraging and respecting my own creativity and ideas.

I would like to thank the members of my thesis committee, Kim E. Innes, Sijin Wen, and Fred Minnear whose collective guidance help shaped this work into a much better project than would have been possible without their help. Many thanks for freely giving their effort and time and for always showing genuine interest in this work. Their comments, critical appraisal, ideas and insights have been valuable.

Special thanks to Dr. Innes for critical appraisal and valuable suggestions for this thesis to be completed.

I also need to specially thank Dr. Wen for helping me with the statistics and analyzing the data. 
I also need to thank Dr. Uma Sundaram for giving me the opportunity to work with him in this research project, without him this project would not have started.

I would like to thank Ravi Juluri, fellow in Gastroenterology, who helped me in data analysis.

I also need to thank my family, mom- Vasumathi and wife - Teja, whose help and support have been invaluable. 
TABLE of CONTENTS

Page No.

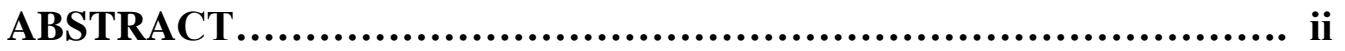

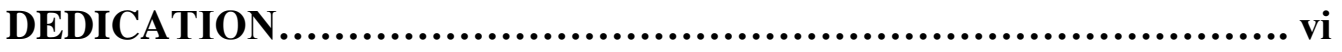

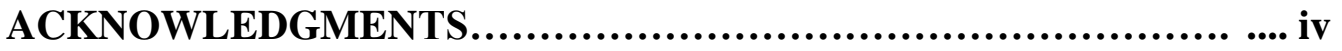

TABLE OF CONTENTS.............................................. vii

LIST OF FIGURES................................................... vii

LIST OF TABLES $\ldots \ldots \ldots \ldots \ldots \ldots \ldots \ldots \ldots \ldots \ldots \ldots \ldots \ldots \ldots \ldots \ldots \ldots \ldots \ldots \ldots . . . \ldots$ viii

ABBREVIATIONS..................................................... viii

CHAPTER

IS A FOLLOW UP ENDOSCOPIC RETROGRADE

CHOLANGIOGRAPHY PROCEDURE NECESSARY FOR REMOVAL OF BILIARY STENT?

1. INTRODUCTION................................................. 1

2. METHODS......................................................... 3

- Data abstraction................................................ 4

- Definitions..................................................... 4

- Statistical analysis.............................................. 5

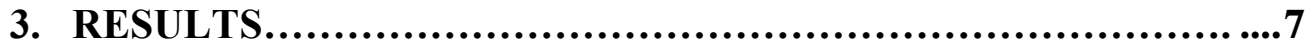

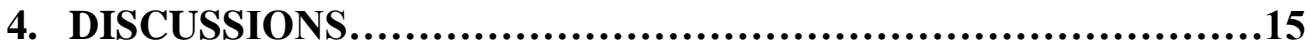

5. CONCLUSIONS......................................................18

6. REFERENCES.......................................................19 


\section{LIST OF FIGURES}

\section{Page number}

Figure 1. Schematic design of the subjects included and excluded in the study. .6

Figure 2. Bar-Plot presentation of follow-up ERCP findings among various diagnoses groups...................................................... 14 


\section{LIST OF TABLES}

Page number

Table 1. Demographics of the subjects by diagnoses group.................9

Table 2. Findings and interventions performed during Initial and follow up

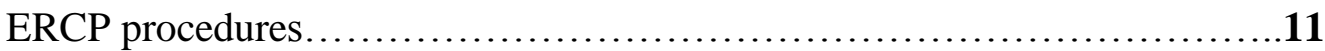

Table 3. Normal and abnormal findings by diagnoses group and Statistical

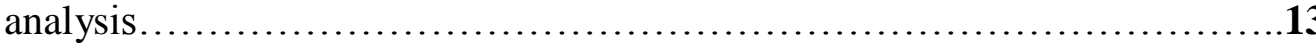




\section{LIST OF ABBREVIATIONS}

\begin{tabular}{|c|c|}
\hline EGD & Esophagogastroduodenoscopy \\
\hline IDR & Integrated Data Repository \\
\hline BL & Bile Leak \\
\hline CDL & Choledocholithiasis \\
\hline BS & Benign Stricture/Obstruction \\
\hline BL/S/S & Benign Pathology with Stone or Stricture \\
\hline & Malignant Stricture/Obstruction \\
\hline & \\
\hline
\end{tabular}


IS A FOLLOW UP ENDOSCOPIC RETROGRADE CHOLANGIOGRAPHY PROCEDURE NECESSARY FOR REMOVAL OF BILIARY STENT? 


\section{INTRODUCTION:}

Endoscopic retrograde cholangiopancreatography (ERCP) is the preferred procedure for purposes of diagnosis and therapy in pathological conditions of biliary and pancreatic origin. In particular, ERCP is generally performed to treat obstructive jaundice due to common bile and/or pancreatic duct obstruction. While ERCP has been used to treat obstructions of varying etiologies, stone removal using ERCP is most commonly performed in patients with choledocholithiasis ${ }^{1}$. Usually, a biliary stent is deployed after cleaning the common bile duct (CBD) either by evacuating stones or by dilatation of the stricture. The stent is placed temporarily and should be removed after a certain period of time with either repeat ERCP or side viewing EGD. Bile leak is a complication secondary to iatrogenic trauma during cholecystectomy that occurs in $2 \%$ of cases $^{2}$ or blunt trauma to the abdomen. The common modality of treatment for bile leak is to use ERCP for placing a biliary stent to cover the leak ${ }^{3,4}$. Although the optimal length of time for stent removal is not known, the stent is usually removed within 3-8 weeks after ensuring the complete healing of the bile leak ${ }^{4}$. Benign and malignant strictures of the biliary tree are other frequent complications that require ERCP for cholangiography, dilatation, cytology brushings and stent placement ${ }^{1}$. The standard practice at our institution was to repeat the ERCP in 6-8 weeks following the initial procedure to assess 
improvement, determine potential complications, and perform any required procedures, including stent removal or exchange.

While ERCP is widely used and may be necessary in certain settings, there are also challenges associated with ERCP procedures. For example, expertise in ERCP requires extensive training and experience in both diagnostic and therapeutic ERCP procedures ${ }^{5}$. The endoscopist must be prepared and competent to perform any indicated therapeutic intervention(s) at the time of diagnostic ERCP procedure ${ }^{6}$. ERCP procedures are associated with significantly greater morbidity and mortality than EGD even when performed by highly skilled clinicians $^{1,7}$. In addition, the complication rate for ERCP is higher than that of all other commonly performed endoscopies ${ }^{8}$. Complications are both procedure- and anesthesia-related ${ }^{9,10}$. The cost of the ERCP is also much higher than those of regular endoscopy ${ }^{11,12}$.

Biliary stents can be removed either by ERCP or by side viewing EGD $^{13,14}$. However, there have been very few studies comparing the effectiveness of EGD to ERCP in removal of biliary stents, and currently specific recommendations for use of EGD vs ERCP are lacking. Simply removing the stents is feasible with EGD, a procedure which is less costly, technically less challenging, more comfortable for the patient and safer from a sedation perspective than ERCP. In this retrospective chart review study, we assessed the 
utility of follow up ERCP to help determine if EGD can serve as a cost effective alternative to ERCP for stent removal. We conducted this study to investigate the role of ERCP in the management of patients with biliary stents; in addition, we conducted an in depth evaluation to determine if follow up ERCP procedure is necessary for biliary stent removal and to identify the conditions for which follow up cholangiography may be absolutely required at the time of stent removal.

\section{METHODS:}

Potential subjects for the research study were identified from the West Virginia integrated data repository (IDR), a centralized electronic database that pools clinical information from sources throughout the state. All data are deidentified to protect patient confidentiality. The database was queried to obtain a list of all adults above eighteen years of age who had undergone ERCP for stent placement and stent removal (CPT codes 43268 and 43269) at the WVU Endoscopy Center at Ruby Memorial Hospital between January 2005 and December 2011. All charts were evaluated in detail and pertinent information gathered, including that regarding demographics, diagnosis based on imaging and ERCP findings, indications for the procedure, procedural findings and type of intervention used. Patients who underwent biliary stent placement at an outside facility, or pancreatic stent placement or exchange, as well as patients lost to 
follow up were excluded from the analysis. This study was approved by the Institutional Review Board (Tracking \# H-20344) at West Virginia University, Morgantown, WV.

\section{Data abstraction}

Medical records of the subjects were accessed by the principal investigator. Pertinent data on each patient were entered into a Microsoft excel spreadsheet using a standardized template, including information on: demographics, initial diagnosis, indication for the procedure, findings and interventions performed and date of the ERCP procedure, as well as follow-up ERCP findings and interventions. The time interval between the ERCP was also measured. Data were pooled based on the diagnosis and specific interventions performed.

\section{Definitions}

For each patient, age was defined as the age at the date of initial ERCP procedure. Diagnosis of the condition was determined based on findings from imaging, the initial ERCP and pathology reports. Patients were categorized into five groups based on the following presenting diagnoses- bile leak, 
choledocholithiasis, benign stricture, malignant stricture and bile leak with stone or stricture. Bile leak generally occurs as a complication of the cholecystectomy or in response to blunt trauma to the abdomen. Spontaneous bile leaks are very rare.

\section{Statistical analysis}

All data analyses were performed using statistical software R (ref). Descriptive statistical analyses were performed to characterize the study population, including mean with standard deviation (or median with range) for continuous variables and proportions or contingency tables for categorical variables. The variables of interest include patient diagnoses and complications, time intervals between the initial and follow-up ERCP, and procedures performed. A consort diagram was used to describe the schematic design of the study population. A bar-plot was used to display the ERCP findings among various diagnoses groups. Chi Square test or Fishers Exact tests were used to determine between group differences in categorical variables; and t-tests were used to investigate between-group difference in continuous variables. Statistical analyses were considered significant if $\mathrm{p}$-value was less than 0.05 . 


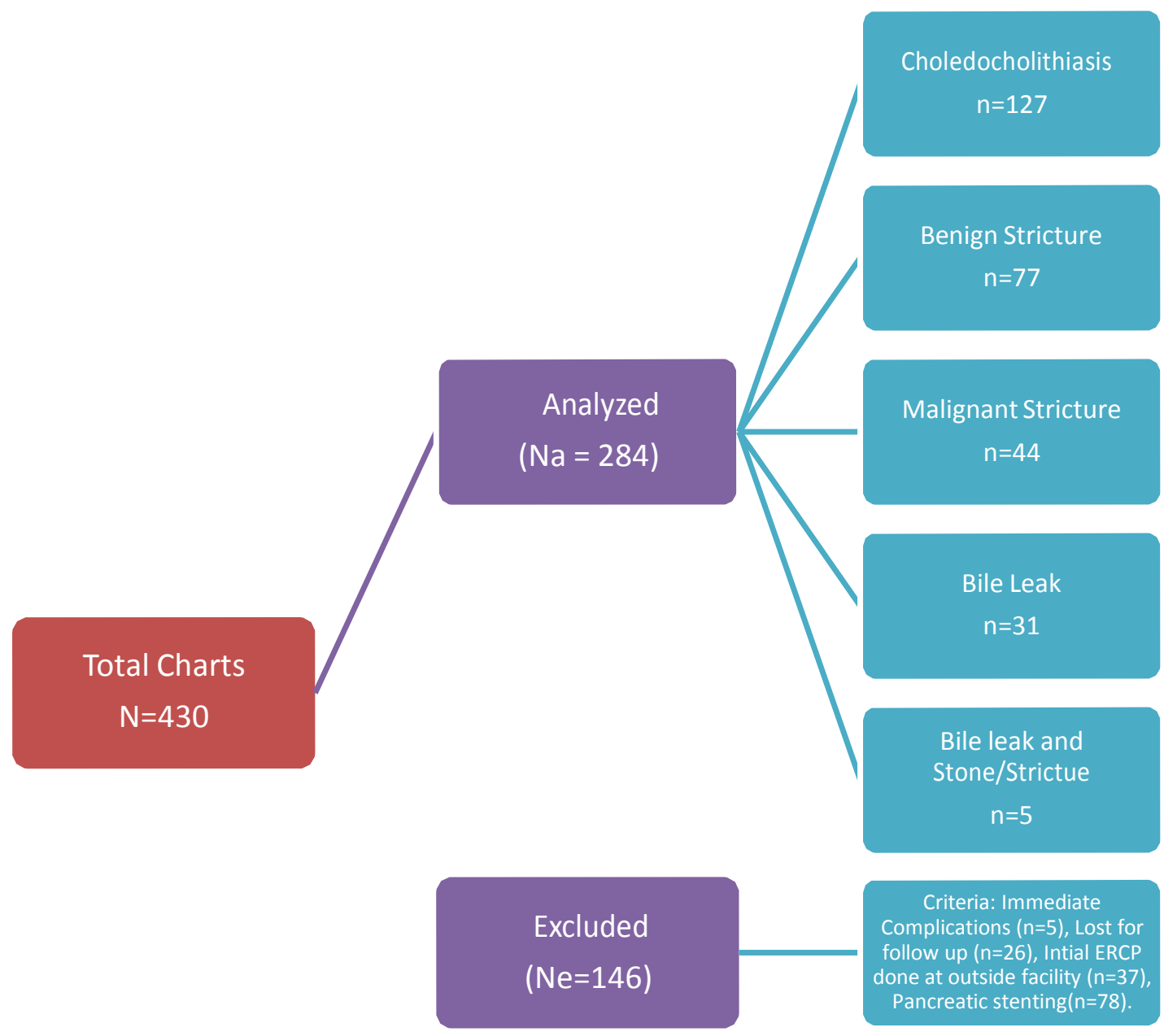

Figure 1: Schematic design of the subjects included and excluded in the study 


\section{RESULTS:}

A total of 430 patients underwent ERCP procedure for various conditions during the period between 1 January 2005 and 31 December 2011. Of these patients, 146 did not meet our inclusion criteria, yielding a final sample of 284 eligible adults (Figure 1). Of the 146 excluded patients, five had complicated initial ERCP procedure with multiple complications requiring immediate follow up ERCP; 37 had stent placement in an outside facility; 26 were lost to follow up; and 78 had pancreatic stent placement and/or exchange.

Subjects were categorized into five diagnostic groups based on findings from initial ERCP procedure; these included Bile leak $(\mathrm{N}=31)$, Choledocholithiasis $(\mathrm{N}=127)$, Benign stricture $(\mathrm{N}=77)$, Malignant stricture $(\mathrm{N}=44)$ and Bile leak with Stone or Stricture $(\mathrm{N}=5)$. Of the 5 patients in bile leak with stone or stricture group, four had microlithiasis (including stone/sludge), and one had stricture of the CBD as secondary findings.

Patient demographics, overall and by group are given in Table 1. Patients ranged from 15 to 90 years of age with a mean age of $59( \pm 19)$ years; $41 \%$ were male. Age varied substantially among groups, with group means ranging from $45.4( \pm 19.34)$ years in those with simple bile leak to $66.5( \pm 11.7)$ years in those with malignant stricture. Average age in the bile leak group was significantly 
lower than that in all other groups $(\mathrm{P}<0.001)$. There was no significance between group differences in gender distribution ( $\mathrm{P}$ 's $>0.5$, Fisher exact test) (Table 1).

All the patients (100\%) analyzed had follow-up ERCP for stent removal. Ninety six percent $(272 / 284)$ of the patients underwent sphincterotomy during the initial procedure; in contrast, only 24 patients underwent sphincterotomy during their follow up ERCP. Of these 24 patients, 9 did not have spinchterotomy performed during the initial ERCP procedure. The remaining 15 patients underwent an extension of sphincterotomy.

The most common intervention performed during follow up ERCP was sludge or stone removal, followed by dilatation and brushings and stent placement. One patient with bile leak and stricture underwent extension sphincterotomy during follow up ERCP. None of the patients in the uncomplicated bile leak group $(n=31)$ had sphincterotomy during follow up ERCP. The time interval between stent placement and removal/exchange ranged from 4 to 303 days, with a median time interval of 77 days. The median time interval was significantly lower in the malignant stricture group than in the remaining groups $(\mathrm{p}=<0.007$; two-sample $\mathrm{t}$-test $)$. All patients with malignant stricture $44(100 \%)$ required stent exchanges with metallic stent in follow up ERCP. 
Table 1: Demographics of the subjects by diagnoses group

\begin{tabular}{|l|c|c|c|c|} 
& Total (N) & Male, $\mathrm{n}(\%)$ & Age range & Mean age (SD) \\
\hline Bile Leak & 31 & $16(52)$ & $18-80$ & $45.4(19.34)$ \\
\hline Stone & 127 & $51(40)$ & $15-89$ & $59.0(20.62)$ \\
\hline Stricture(benign) & 77 & $27(35)$ & $23-90$ & $61.0(17.78)$ \\
\hline BL/S/S & 5 & $3(60)$ & $56-79$ & $65.0(8.98)$ \\
\hline Malignant Stricture & 44 & $20(45)$ & $45-90$ & $66.5(11.68)$ \\
\hline Benign Pathology & 240 & $97(40)$ & $15-90$ & $57.7(19.93)$ \\
\hline & & & & \\
\hline Total & 284 & $117(41)$ & $15-90$ & $59.1(19.11)$ \\
\hline
\end{tabular}

Table 1: Demographics: Stone - Choledocholithiasis, BL/S/S - Bile leak with Stone or stricture, Benign pathology $(\mathrm{BP})=$ Total - Malignant stricture. SD- Standard deviation. Age group was significantly lower in Bile leak group compared to all other groups $(\mathrm{p}<0.001)$. No significant group differences in gender distribution $(\mathrm{p}>0.05)$. 
All patients in Bile leak group with Stone or Stricture had abnormal pathology during follow up ERCP, requiring intervention only possible using ERCP. One patient had benign CBD stricture with further dilatation, brushings and stent exchange performed during follow up ERCP; after 64 days, a third ERCP was needed for stent removal after ensuring adequate patency of CBD. The remaining four patients had stone/sludge along with bile leak at the time of initial ERCP. Although the sludge/stone was extracted during initial ERCP, all four required intervention with sludge extraction during follow up ERCP.

Of the 31 patients in Bile leak group, 26 (84\%) had normal ERCP and completely healed bile leak, requiring no further intervention at follow-up. The remaining five patients had abnormal findings at follow-up ERCP, including one with persistent bile leak at a 34 day follow up ERCP; this patient was successfully treated with placement of a stent, which was removed at 6 weeks following ERCP confirmation of complete healing. The remaining four patients had sludge extracted during the second ERCP procedure, although initial ERCP procedure notes did not indicate stone or sludge extraction. All cases of bile leak were due to complications of cholecystectomy. 
Table 2: Findings and Interventions performed during initial and follow up ERCP Procedures.

\begin{tabular}{|c|c|c|c|c|c|c|c|}
\hline & BL & CDL & BS & BL/S/S & BP & MS & TOTAL \\
\hline Total, N & 31 & 127 & 77 & 5 & 240 & 44 & 284 \\
\hline $\begin{array}{c}\text { Median Time } \\
\text { interval between } \\
\text { ERCP's - in days } \\
\text { (Range) }\end{array}$ & $\begin{array}{c}97 \\
(27-190)\end{array}$ & $\begin{array}{c}77 \\
(7-193)\end{array}$ & $\begin{array}{c}64 \\
(5-252)\end{array}$ & $\begin{array}{c}87 \\
(76-145)\end{array}$ & $\begin{array}{c}80 \\
(5-252)\end{array}$ & $\begin{array}{c}37 \\
(4-303)\end{array}$ & $\begin{array}{c}77 \\
(4-303)\end{array}$ \\
\hline $\begin{array}{c}\text { Normal result on } \\
\text { repeat ERCP n } \\
(\%)\end{array}$ & $26(84)$ & $13(10)$ & $14(18)$ & $0(0)$ & $53(22)$ & $0(0)$ & $53(19)$ \\
\hline $\begin{array}{c}\text { Dilatation/ } \\
\text { Brushings/Balloon } \\
\text { extraction } \\
\text { n }(\%)\end{array}$ & $4(13)$ & $108(85)$ & $54(70)$ & $4(80)$ & $170(71)$ & $11(25)$ & 181(64) \\
\hline $\begin{array}{c}\text { Sphincterotomy } \\
\text { n }(\%)\end{array}$ & $0(0)$ & $12(9)$ & $7(9)$ & $1(20)$ & $20(8)$ & $4(9)$ & $24(8)$ \\
\hline $\begin{array}{c}\text { Stent Placement } \\
\text { n }(\%)\end{array}$ & $1(3)$ & $23(18)$ & $31(40)$ & $1(20)$ & $56(23)$ & $44(100)$ & $100(35)$ \\
\hline
\end{tabular}

Table 2: Procedural therapies performed in different groups in follow up ERCP. BL - Bile leak, CDLCholedocholithiasis and Microlithiasis, BS- Benign stricture, BL/S/S - Bile leak with Stone or Stricture, MS-

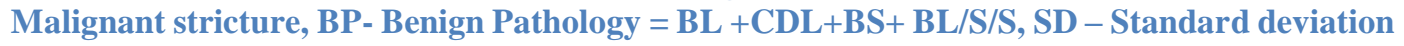


As shown in table 3, findings at follow-up ERCP were abnormal in a significantly lower percentage of patients with uncomplicated bile leak(16\% $(5 / 31))$ than in those with Choledocholithiasis- $(90 \%(114 / 127))(\mathrm{p}<0.0001)$, Benign stricture $(82 \%(63 / 77))(\mathrm{p}<0.0001)$, bile leak with stone or stricture $(100 \%$ $(5 / 5))(\mathrm{p} 0.0007)$, or malignant stricture $(100 \%(44 / 44))(\mathrm{p}<0.0001)$. Eighty-four $\%(26 / 31)$ of the patients with uncomplicated bile leak had normal findings on repeat ERCP, whereas only $10 \%$ of the patients with choledocholithiasis and $18 \%$ with benign stricture had normal findings on repeat ERCP. Interestingly, none $(0 \%)$ of the patients in malignant obstruction group or Bile leak with Stone or Stricture group had normal findings on repeat ERCP. 
Table 3: Normal and abnormal findings of follow up ERCP by diagnoses group and statistical analysis.

\begin{tabular}{|c|c|c|c|c|c|}
\hline & $\begin{array}{c}\text { Bile Leak } \\
\mathbf{n}(\%)\end{array}$ & $\begin{array}{c}\text { Choledocho- } \\
\text { lithiasis } \\
\mathbf{n}(\%)\end{array}$ & $\begin{array}{c}\text { Benign } \\
\text { Stricture } \\
\mathbf{n}(\%)\end{array}$ & $\begin{array}{c}\text { Bile leak + } \\
\text { Stone/stricture } \\
\mathbf{n}(\%)\end{array}$ & $\begin{array}{c}\text { Malignant } \\
\text { Stricture } \\
\mathbf{n}(\%)\end{array}$ \\
\hline $\begin{array}{c}\text { Normal } \\
\mathrm{N}=53\end{array}$ & $26(84)$ & $13(10)$ & $14(18)$ & $0(0)$ & $0(0)$ \\
\hline $\begin{array}{c}\text { Abnormal } \\
\mathrm{N}=231\end{array}$ & $5(16)$ & $114(90)$ & $63(82)$ & $5(100)$ & $44(100)$ \\
\hline p-value & ref & $<0.0001$ & $<0.0001$ & 0.0007 & $<0.0001$ \\
\hline
\end{tabular}

Table 3: Statistical analysis between normal and abnormal findings, Normal: no leak or obstruction or strictures in follow up ERCP. Abnormal: either leak or stone or stricture in follow up ERCP requiring intervention. 


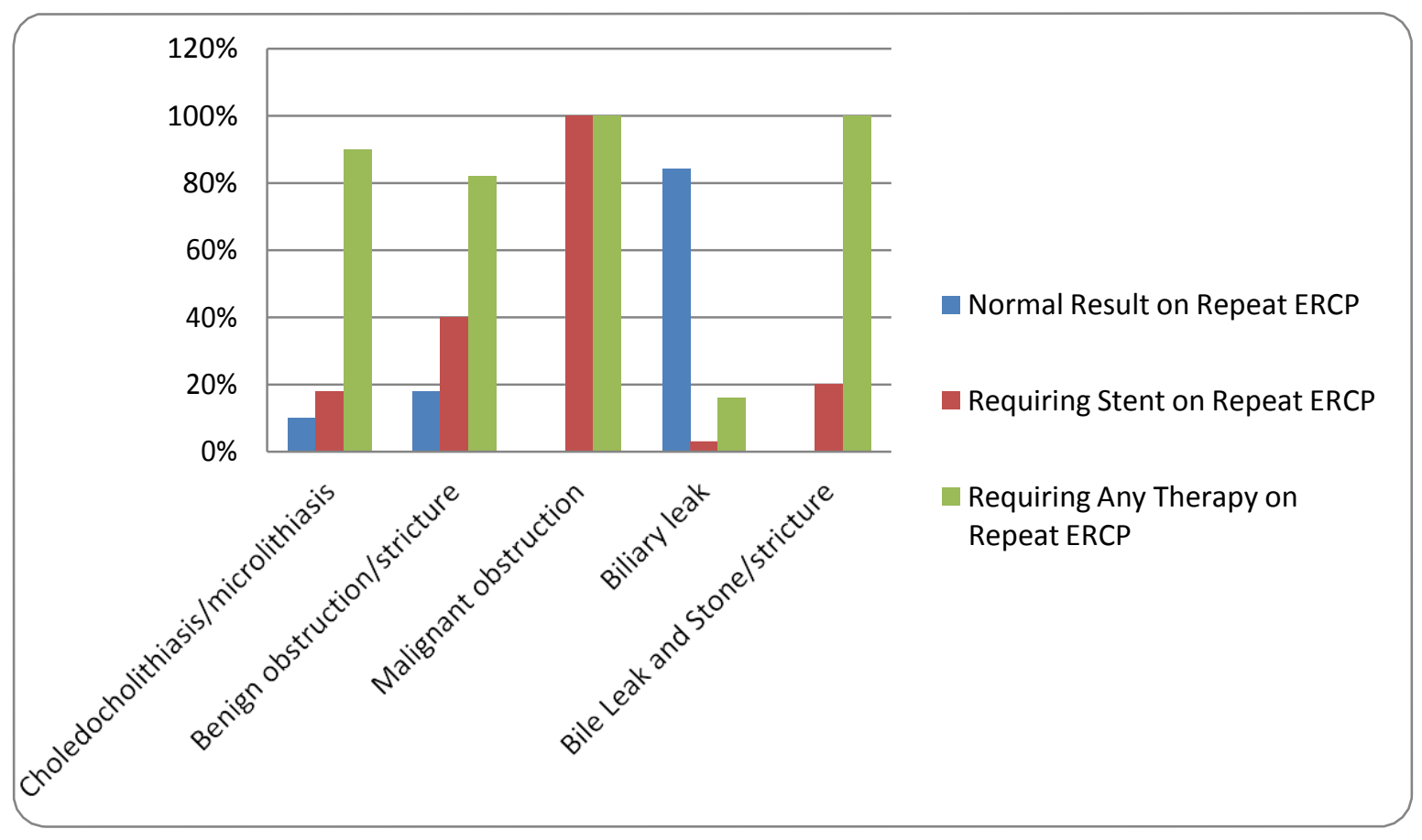

Figure 2. Bar-plot of follow-up ERCP findings among various diagnoses groups. 


\section{DISCUSSION:}

Biliary stent placement is a common endoscopic procedure for various biliary pathologies by conventional ERCP. ERCP is associated with several life threatening complications, including those directly related to the procedure ${ }^{8,15}$ and those related to anesthesia ${ }^{10,16}$. In addition, the cost of ERCP is much higher than that of regular $\mathrm{EGD}^{14,17,18}$. The procedure is also challenging to perform, requiring extensive training and experience. Given these drawbacks, we conducted a study using existing patient data to determine if ERCP is necessary for stent removal in all patient populations. We performed a retrospective chart review in all patients who underwent stent removal and compared findings, for 5 patient groups, of initial and follow up ERCP. Our study results suggest that, in all but patients with simple bile leak, repeat ERCP is likely necessary as a follow up procedure for stent removal as most will require therapy along with stent removal, which can be accomplished only with ERCP. However, in patients with uncomplicated bile leak, use of a regular side viewing EGD would likely be sufficient to remove the stent in the vast majority of cases.

Complications of ERCP include pancreatitis, hemorrhage, cholangitis, septicemia ${ }^{19}$, perforation and various other complications such as recurrent stone formation and sphincterotomy stenosis ${ }^{8,20,21}$. Pancreatitis occurs in $6.7 \%$ of general population and in up to $15-30 \%$ of high-risk patients ${ }^{22}$. Bleeding is seen 
endoscopically in $10-30 \%$ of the patients undergoing Sphincterotomy ${ }^{23}$. Perforation is reported in less than $1 \%$ of the patients undergoing ERCP and sphincterotomy ${ }^{24-26}$.

Previous findings regarding need for ERCP during stent removal in patients with bile leak have been inconsistent, rendering the establishment of specific recommendations for use of ERCP vs EGD challenging. For example, Coelho and Baron showed good results for stent removal with EGD in their recent study of 64 post bile leak patients ${ }^{14}$. In contrast, Jain et al showed significant abnormalities requiring ERCP for stent removal in their investigation of 80 bile leak patients ${ }^{13}$. This inconsistency in findings may in part reflect differences in patient populations. However, to our knowledge, no previous studies have investigated potential variation in outcome and associated need for ERCP at stent removal in different patient diagnostic groups.

Several studies have reported costs of ERCP procedures to substantially exceed those of regular endoscopy procedure ${ }^{12,17,18}$. Likewise, we found similar cost discrepancies in our analysis of ERCP and EGD billing data from the WVU Endoscopy center using Medicare/Medicaid reimbursement rates. Costs for ERCP with stent removal using Code 43269 are $\$ 2163.76$ vs. $\$ 977.13$ for an EGD with stent removal/intervention (coded as 43267), a difference of $\$ 1186.63$ per procedure. These figures are consistent with the findings of Coelho et al., who 
showed that approximately $\$ 500,000$ a year can be saved using EGD rather than ERCP for stent removal in patients with biliary leak ${ }^{14}$.

In our study, more than $90 \%$ of patients with choledocholithiasis, benign stricture, malignant stricture and bile leak with stricture or stone required repeat ERCP. However, in patients with simple bile leak, only $16 \%$ needed intervention requiring ERCP; of those requiring subsequent therapy, four of them required sludge removal and the initial ERCP procedure notes failed to mention if there was any sludge or stone extracted, and in the $5^{\text {th }}$ case, stent removal was likely performed too soon; the low complication rate in those with simple bile leak suggests that stent removal using EGD may be a viable and cost-effective alternative for these patients.

Our study has several limitations. Findings are based on retrospective data, and miscategorization remains possible. Relative to other groups, sample size in the bile leak group was relatively small, and thus our findings, while consistent with previous research, must be interpreted with caution. While we collected data on a large number of patients undergoing stent placement and removal using ERCP, we lacked information on outcomes of stent removal using EGD. Clearly, a larger, prospective study is needed to determine if EGD might be a cost effective substitute for ERCP in uncomplicated bile leak patients, and possibly other patient groups. Studies are also needed to identify specific high 
risk patient populations most likely to need follow-up interventions requiring ERCP in Bile leak group. Our findings strongly suggest that bile leak patients with sludge, microlithiasis or stricture during initial ERCP procedure will require follow up ERCP procedure to assess adequate resolution of associated pathology along with primary pathology. In these patients, complete extraction of the bile sludge during initial procedure would be beneficial, but would likely still not preclude using ERCP for stent removal.

\section{CONCLUSION}

In this retrospective chart review study of 284 patients undergoing stent removal, our findings suggest a repeat ERCP for stent removal will be required for over $90 \%$ of patients with a diagnosis of choledocholithiasis, benign stricture, malignant stricture and complicated bile leak. However, the low complication rates observed in patients with uncomplicated bile leak suggest that, for these patients, a regular side viewing EGD may provide a safer and more cost effective alternative to ERCP. Larger prospective studies should be conducted to clearly identify the risk factors that indicate the need for ERCP vs a regular EGD in patients with bile leak and possibly other conditions. 


\section{$\underline{\text { References: }}$}

1. Adler DG, Baron TH, Davila RE, et al. ASGE guideline: the role of ERCP in diseases of the biliary tract and the pancreas. Gastrointestinal endoscopy. 2005;62(1):1-8.

2. Barkun AN, Rezieg M, Mehta SN, et al. Postcholecystectomy biliary leaks in the laparoscopic era: risk factors, presentation, and management. McGill Gallstone Treatment Group. Gastrointestinal endoscopy. 1997;45(3):277-282.

3. Spinn MP, Patel MK, Cotton BA, Lukens FJ. Successful endoscopic therapy of traumatic bile leaks. Case reports in gastroenterology. 2013;7(1):56-62.

4. Singh V, Narasimhan KL, Verma GR, Singh G. Endoscopic management of traumatic hepatobiliary injuries. Journal of gastroenterology and hepatology. 2007;22(8):1205-1209.

5. NIH state-of-the-science statement on endoscopic retrograde cholangiopancreatography (ERCP) for diagnosis and therapy. $\mathrm{NIH}$ consensus and state-of-the-science statements. 2002;19(1):1-26.

6. Principles of training in gastrointestinal endoscopy. From the ASGE. American Society for Gastrointestinal Endoscopy. Gastrointestinal endoscopy. 1999;49(6):845-853.

7. ASGE guidelines for clinical application. The role of ERCP in diseases of the biliary tract and pancreas. American Society for Gastrointestinal Endoscopy. Gastrointestinal endoscopy. 1999;50(6):915-920.

8. Freeman ML. Understanding risk factors and avoiding complications with endoscopic retrograde cholangiopancreatography. Current gastroenterology reports. 2003;5(2):145-153.

9. American Society of Anesthesiologists Task Force on S, Analgesia by NA. Practice guidelines for sedation and analgesia by non-anesthesiologists. Anesthesiology. 2002;96(4):1004-1017. 
10. Lee TH, Lee CK, Park SH, et al. Balanced propofol sedation versus propofol monosedation in therapeutic pancreaticobiliary endoscopic procedures. Digestive diseases and sciences. 2012;57(8):2113-2121.

11. Andersson R, Eriksson K, Blind PJ, Tingstedt B. Iatrogenic bile duct injury--a cost analysis. $H P B$ : the official journal of the International Hepato Pancreato Biliary Association. 2008;10(6):416-419.

12. Woods MS. Estimated costs of biliary tract complications in laparoscopic cholecystectomy based upon Medicare cost/charge ratios. A case-control study. Surgical endoscopy. 1996;10(10):1004-1007.

13. Jain V, Yeasted N, Pooran N. Necessity of a repeat cholangiogram during biliary stent removal after postcholecystectomy bile leak. Canadian journal of gastroenterology = Journal canadien de gastroenterologie. 2012;26(10):701-704.

14. Coelho-Prabhu N, Baron TH. Assessment of need for repeat ERCP during biliary stent removal after clinical resolution of postcholecystectomy bile leak. The American journal of gastroenterology. 2010;105(1):100-105.

15. Freeman ML, DiSario JA, Nelson DB, et al. Risk factors for post-ERCP pancreatitis: A prospective, multicenter study. Gastrointestinal endoscopy. 2001;54(4):425-434.

16. Garewal D, Powell S, Milan SJ, Nordmeyer J, Waikar P. Sedative techniques for endoscopic retrograde cholangiopancreatography. The Cochrane database of systematic reviews. 2012;6:CD007274.

17. Van Steenbergen W, Van Aken L, Volders W, Kesteloot K. Cost analysis of ERCP in a university hospital. Gastrointestinal endoscopy. 2001;53(2):152-160.

18. Walker RS, Vanagunas AD, Williams P, Chodash HB. Therapeutic ERCP: a cost-prohibitive procedure? Gastrointestinal endoscopy. 1997;46(2):143146.

19. Motte S, Deviere J, Dumonceau JM, Serruys E, Thys JP, Cremer M. Risk factors for septicemia following endoscopic biliary stenting. Gastroenterology. 1991;101(5):1374-1381. 
20. Freeman ML, Nelson DB, Sherman S, et al. Complications of endoscopic biliary sphincterotomy. The New England journal of medicine. 1996;335(13):909-918.

21. Carr-Locke DL. Overview of the role of ERCP in the management of diseases of the biliary tract and the pancreas. Gastrointestinal endoscopy. 2002;56(6 Suppl):S157-160.

22. Freeman ML, DiSario JA, Nelson DB, et al. Risk factors for post-ERCP pancreatitis: a prospective, multicenter study. Gastrointestinal endoscopy. 2001;54(4):425-434.

23. Nelson DB, Freeman ML. Major hemorrhage from endoscopic sphincterotomy: risk factor analysis. Journal of clinical gastroenterology. 1994;19(4):283-287.

24. Loperfido S, Angelini G, Benedetti G, et al. Major early complications from diagnostic and therapeutic ERCP: a prospective multicenter study. Gastrointestinal endoscopy. 1998;48(1):1-10.

25. Trap R, Adamsen S, Hart-Hansen O, Henriksen M. Severe and fatal complications after diagnostic and therapeutic ERCP: a prospective series of claims to insurance covering public hospitals. Endoscopy. 1999;31(2):125-130.

26. Tzovaras G, Shukla P, Kow L, Mounkley D, Wilson T, Toouli J. What are the risks of diagnostic and therapeutic endoscopic retrograde holangiopancreatography? The Australian and New Zealand journal of surgery. 2000;70(11):778-782. 
